\title{
O comentário esportivo no rádio de Porto Alegre: uma proposta de periodização histórica ${ }^{1}$
}

\author{
Carlos Gustavo Soeiro GUIMARÃES ${ }^{2}$ \\ Luiz Artur FERRARETTO ${ }^{3}$
}

\begin{abstract}
Resumo:
Apresenta uma proposta de periodização histórica do comentário esportivo no rádio de Porto Alegre, baseando-se em parâmetros para esse tipo de estudo propostos por Agnes Heller (1997). Considera, para tanto, como pontos de corte, as relações do comentário esportivo com os impactos das transformações tecnológicas sob a vigência de mudanças no próprio sistema capitalista. Como base, ampara-se, de modo geral, na economia política da comunicação (MOSCO, 1996), considerando as alterações que levam ao surgimento, na contemporaneidade, de uma fase da multiplicidade da oferta (BRITTOS, 2002), e, especificamente, em reflexões a respeito do rádio dentro desse referencial teórico (FERRARETTO; KISCHINHEVSKY, 2007). Partindo de uma revisão dos dados históricos, busca construir demarcações, delineando a trajetória do comentário esportivo radiofônico na capital do Rio Grande do Sul.

Palavras-chave:

Rádio. Jornalismo esportivo. Gêneros jornalísticos. Economia política da comunicação. História.

\section{Sports commentary on Porto Alegre radio: a proposal for a historical periodization}

\begin{abstract}
:
This article presents a proposal for a historical periodization of sports commentary on Porto Alegre radio stations, based on parameters for this type of study developed by Agnes Heller (1997). It uses as cutoffs, the relationship between sports commentary and the impacts of technological transformation from the perspective of change in the capitalist system itself. It is based, overall, on the political economy of communication (MOSCO, 1996), taking into consideration the changes that are leading to the emergence, nowadays, of a phase of multiplicity of supply (BRITTOS, 2002), and, specifically, on reflections about radio within this theoretical framework (FERRARETTO; KISCHINHEVSKY, 2007). Starting off with a review of historical data, it seeks to create demarcations, outlining the trajectory of sports commentary on radio in the capital of Rio Grande do Sul.

Keywords:

Radio. Sports journalism. Journalistic genres. Political economy of communication. History.

\section{El comentario deportivo en la radio de Porto Alegre: una propuesta de periodización histórica}

Resumen:

Se presenta una propuesta de periodización histórica del comentario deportivo en la radio de Porto Alegre, basándose en parámetros para ese tipo de estudio propuestos por Agnes Heller (1997). Considera, para tanto, como puntos de corte, las relaciones del comentario deportivo con los impactos de las

\footnotetext{
${ }^{1}$ Trabalho apresentado no GP Rádio e Mídia Sonora no XVI Encontro dos Grupos de Pesquisa em Comunicação, evento componente do XXIX Congresso Brasileiro de Ciências da Comunicação. A reflexão aqui exposta integra dissertação de mestrado $O$ comentário esportivo contemporâneo no rádio de Porto Alegre: uma análise das novas práticas profissionais na fase de convergência, concluída em 2018.

2 Mestre pelo Programa de Pós-Graduação em Comunicação e Informação da Universidade Federal do Rio Grande do Sul, Porto Alegre, RS. E-mail: csguimaraes@gmail.com

${ }^{3}$ Professor do Programa de Pós-Graduação em Comunicação e Informação da Universidade Federal do Rio Grande do Sul, Porto Alegre, RS. E-mail: luiz.ferraretto@ufrgs.br.
} 
transformaciones tecnológicas bajo la vigencia de cambios en el propio sistema capitalista. Como base, se ampara, en general, en la economía política de la comunicación (MOSCO, 1996), considerando las alteraciones que llevan al surgimiento, en la contemporaneidad, de una fase de la multiplicidad de la oferta (BRITTOS, 2002), y, específicamente, en reflexiones acerca de la radio dentro de ese referencial teórico (FERRARETTO; KISCHINHEVSKY, 2007). A partir de una revisión de los datos históricos, busca construir demarcaciones, delineando la trayectoria del comentario deportivo radiofónico en la capital de Rio Grande do Sul.

Palabras clave:

Radio. Periodismo deportivo. Géneros periodísticos. Economía política de la comunicación. Historia.

\section{Introdução}

Peça fundamental em uma transmissão de futebol no rádio e na televisão, o comentarista esportivo é o responsável pela tradução dos acontecimentos da partida para o público. Cabe a ele identificar os problemas, apontar possíveis soluções, repassar dados relevantes, intuir sobre projeções necessárias a se fazer a respeito do jogo e opinar acerca de temas que permeiam o confronto entre as duas equipes. Através dos tempos, esses profissionais desenvolveram novos procedimentos e incorporaram elementos no formato de apreensão dos fatos do jogo e da sua transmissão para os ouvintes. Tais transformações incorrem em alterações significativas na história desse tipo de conteúdo, gerando variações em torno dos gêneros jornalísticos e resultando em adaptação de forma e de conteúdo de acordo com as conversões que os processos tecnológicos geram ao longo do tempo.

Nesse sentido, centra-se o foco, aqui, nas possibilidades proporcionadas pela abordagem a partir da economia política da comunicação, que, como descreve Mosco (1996, p. 27-38), caracteriza-se pela: (1) priorização da mudança social e da transformação histórica, passando, necessariamente, por um exame da dinâmica do sistema capitalista; (2) tentativa de compreender a totalidade social, ou seja, a identificação de elos dos campos econômico e político com o amplo entorno cultural e social, sendo, portanto, básica a ideia da observação do objeto de estudo em um contexto mais abrangente; (3) inclusão de uma perspectiva em que se destaca uma espécie de filosofia moral, objetivando explicitar posições éticas a respeito de práticas econômicas e políticas, muitas vezes mascaradas pelos interesses nelas envolvidos; e (4) abordagem considerando a questão da práxis, ou seja, a relação que se estabelece entre o ser humano e seu entorno, produzindo e transformando o mundo e a si mesmo. Nesta breve abordagem, sem desconsiderar cada um deles, ao se descrever o aspecto histórico, o item (1) acaba sendo priorizado, com os demais amparando a análise e a contextualização da reflexão encetada. 
Aproximando-se do estudo histórico, mas considerando, portanto, a economia política da comunicação, ampara-se este recorte do trajeto do rádio em Porto Alegre em trabalho anterior de Ferraretto (2007, p. 22), em sua proposta de "analisar o rádio do Rio Grande do Sul como empresa em busca de lucro, cuja programação interfere culturalmente na sociedade gaúcha”. Parte-se ainda da ideia de vigência de uma fase da multiplicidade da oferta ou seja, de novas lógicas de produção, comercialização, distribuição e consumo de conteúdos radiofônicos em tempos de convergência, nas quais, para efeitos deste estudo, destacam-se a passagem da lógica de oferta para a de demanda, presente, por exemplo, na oferta, via internet, de arquivos de áudios já veiculados, ou a constante participação do ouvinte por redes sociais (BRITTOS, 2002); na multiplicação de ações empresariais para disponibilizar o conteúdo radiofônico nas mais diversas plataformas tecnológicas; e na sinergia da emissora com outros veículos dentro de um mesmo grupo empresarial (FERRARETTO; KISCHINHEVSKY, 2007).

É importante abordar os gêneros jornalísticos, cruciais para a compreensão do que vai ser proposto, uma vez que cada fase tem como característica primordial a inflexão para um ou outro deles. Adota-se a categorização apresentada por Melo (MELO; ASSIS, 2010, p. 23-41), que parte da ideia de gênero jornalístico como um conjunto de parâmetros textuais identificados com base nos seus propósitos comunicativos. Assim, usando como base, ainda, considerações a respeito gêneros no âmbito radiofônico (FERRARETTO, 2014, p. 95-98), têm-se: (1) o informativo, que se limita a narrar o assunto a ser noticiado com o mínimo de detalhes necessários à sua compreensão, sendo dominante no noticiário radiofônico em geral; (2) o interpretativo, representando uma ampliação qualitativa do tratamento dos assuntos a serem repassados ao público e procurando, dessa maneira, situar o ouvinte, ao contextualizar a narrativa, aparecendo na formulação de algumas notas e reportagens ou em participações de apresentadores e de comentaristas, além de programas de entrevistas e mesas-redondas; (3) o opinativo, englobando um julgamento próprio (pessoal ou da empresa de radiodifusão) a respeito de um determinado assunto, presente em comentários, editoriais e, não raro, em intervenções dos âncoras e dos próprios ouvintes; (4) o utilitário, no qual se incluem informações sobre aeroportos, indicadores do mercado financeiro, pagamento de impostos, previsão do tempo, recebimento de aposentadorias e pensões, roteiro cultural, trânsito etc.; e (5) o diversional, correspondendo à incorporação de técnicas de narrativa ficcional na descrição de fatos reais, manifestando-se, de forma 
assistemática, na abordagem adotada em crônicas e em alguns documentários.

\section{Proposta de periodização}

Como base metodológica para a periodização, vai-se ao encontro das recomendações de Agnes Heller na tentativa de identificação de pontos de corte, "algo decisivo que transformou outro acontecimento ou uma série deles em passados e produziu outros futuros" (HELLER, 1997, p. 130), situando-se o estudo no que Schudson (1993, p. 214) denomina de história propriamente dita, ou seja, a descrição analítica da relação dos meios de comunicação com a trajetória cultural, política, econômica ou social, na tentativa de dar conta da questão: "de que modo estes meios influenciam as mudanças na comunicação e como estes são influenciados por outros aspectos das mudanças que vão ocorrendo na sociedade?’.

Parte-se, ainda, da proposta de periodização de Ferraretto (2012) para a história do rádio no Brasil, considerando dados específicos sobre a trajetória do meio no Rio Grande do Sul presentes em trabalhos anteriores (2002/2007): (1) fase de implantação, do final da década de 1910 até a segunda metade da década de 1930, que corresponde à instalação das estações pioneiras, organizadas sob a forma de entidades associativas; na sua sequência, sob a hegemonia do rádio comercial, (2) fase de difusão, do início da década de 1930 até a segunda metade da década de 1960; (3) fase de segmentação, do final da década de 1950 até o início do século 21; e (4) fase de convergência, de meados da década de 1990 até a atualidade. Algumas fases possuem períodos sobrepostos, uma vez que Ferraretto (2012) considera que o processo que determina um ponto de corte é dinâmico e que não há uma ruptura total da fase anterior até a nova fase se tornar hegemônica.

Desenha-se uma linha desde 1931, ano em que foi realizada a primeira transmissão esportiva em Porto Alegre, feita por Ernani Ruschel (FERRARETTO, 2007, p. 478). Considera-se a necessidade de contextualizar o momento em que surgem os comentaristas, descrevendo o funcionamento das transmissões esportivas sem essa figura, nas décadas de 1930 e 1940. A partir disso, eventos relacionados à tecnologia funcionam como rupturas: (1) a popularização dos receptores transistorizados; (2) o televisionamento dos jogos; (3) a internet e, entre outras consequências dela, as redes sociais. Assim, sem deixar de considerar um momento anterior, no qual surgem as irradiações de jogos, mas sem a presença perfeitamente delineada do comentarista, a 
periodização proposta inclui três fases: (1) da crônica esportiva, do início da década de 1950 até o início de 1970; (2) do jornalismo esportivo, de meados de dos anos 1960 até o início do século 21; e (3) do jornalismo esportivo convergente, da segunda metade da década de 1990 até a atualidade. Desse modo, cria-se uma linha do tempo, com separações caracterizadas a partir dos pontos de corte marcantes, procurando ir ao encontro da ideia de compreender a descontinuidade na continuidade, o que, de acordo com Heller (1997, p. 133), "é o princípio organizativo de toda obra historiográfica e, portanto, uma ideia universalmente constitutiva da historiografia”.

\section{Primeiras irradiações}

O modelo atual de jornada esportiva ${ }^{4}$ no rádio de Porto Alegre emprega a seguinte estrutura: narrador, o responsável pela descrição dos lances; comentarista, aquele que tem como função principal a análise dos acontecimentos; repórter, a fornecer informações a partir da observação direta e de entrevistas; e plantão esportivo, o encarregado de abastecer a transmissão com dados do jogo em si e informar sobre outros acontecimentos paralelos. Tal padrão é facilmente identificável em quatro rádios da capital do Rio Grande do Sul que fazem transmissões esportivas: Band, Gaúcha, Guaíba e Grenal. Trata-se de um modelo que começou a ser construído em 1931, quando Ernani Ruschel descreveu, no antigo Estádio da Baixada ${ }^{5}$ a vitória do Grêmio Foot-ball Porto-Alegrense por 3 a 1 frente à seleção do Paraná (FERRARETTO, 2002, p. 220).

Durante as décadas de 1930 e 1940, não existia especificamente o papel do comentarista como nos moldes atuais. A própria transmissão inaugural realizada por Ruschel foi marcada pela precariedade informativa. Improvisado como narrador, o radialista descreve lance a lance graças ao desportista Ary Lund, que vai indicando os nomes dos jogadores ao seu ouvido, não havendo registros da participação efetiva desse último ao microfone (MARTINS, 1991, p. 9).

Até meados da década de 1950, “o narrador constitui-se em figura não só predominante como na atualidade, mas, na época, praticamente exclusiva na transmissão dos jogos de futebol” (FERRARETTO, 2007, p. 478). De acordo com Dalpiaz (2002, p. 65), até aquela época, “o trabalho do comentarista era semelhante ao do repórter de campo [grifo do autor] de hoje: visitava o vestiário, conversava com os

\footnotetext{
${ }^{4}$ A transmissão da partida em si.

${ }^{5}$ Situado onde hoje se encontra o parque Moinhos de Vento, um dos principais de Porto Alegre.
} 
jogadores e reunia as informações para auxiliar o locutor durante a narração". Não havia cabines de rádio nos estádios de Porto Alegre que possibilitassem uma visão ampla do jogo. A transmissão em si se adaptou, portanto, às condições existentes nesses locais, preponderando a chamada narração em diagonal:

Como na época a irradiação é feita a partir da beira do gramado, um dos narradores posiciona-se de um lado e o outro, na sua diagonal, à esquerda, cabendo a cada um descrever os lances da metade do campo de jogo a sua frente. A alternância ocorre no momento em que a bola atravessa a linha divisória. (FERRARETTO, 2007, p. 478).O comentarista da época tinha uma função que não era prioritariamente a de analisar os procedimentos táticos e o desenvolvimento técnico de uma equipe. É o que descreve Martins (1991, p. 12), a partir de uma série de entrevistas com profissionais que iniciaram suas carreiras nas décadas de 1950 e 1960:

A participação do comentarista era insignificante. Fazia uma análise emocional, não existia o comentarista técnico. O comentarista falava como se fosse um torcedor do espetáculo, fazendo observações sobre as circunstâncias da partida e não sobre a técnica do jogo (MARTINS, 1991, p. 12). A Copa do Mundo de 1950, realizada no Brasil, estimulou a cobertura esportiva por emissoras de rádio, embora, como salienta Ferraretto (2002, p. 224-225), o jornalismo em geral e o esportivo em particular ocupassem uma posição minoritária em termos de interesse até a década de 1960, sobrepujados pelas novelas, humorísticos e programas de auditório. A respeito, observou o comentarista Ênio Melo (1992 apud DALPIAZ, 2002, p. 72), um dos pioneiros da função no estado:

\begin{abstract}
O fracasso do futebol brasileiro em 1950 gerou uma ânsia de reabilitação. E é neste ponto que eu não sei dizer se foi o rádio que fez a grandeza do futebol ou o futebol fez a grandeza do rádio. À medida que o rádio divulgava, o futebol tomava conta do povo e estimulava políticos, empresários e as emissoras de rádio. $\mathrm{O}$ futebol começou a receber dinheiro e apoio de pessoas desejosas de fazer carreira sobre a alavanca de popularidade de um esporte que surgia. (MELO, 1992 apud DALPIAZ, 2002, p. 72).
\end{abstract}

Impulsionada pela construção do Maracanã no final da década de 1940, a estrutura dos estádios também começou a se modificar. No Rio Grande do Sul, como destaca Dalpiaz (2002, p. 76), o rádio esportivo passou a contar com cabines para a transmissão de jogos a partir de 1954, com a inauguração do Estádio Olímpico. A novidade permitiu aos profissionais de microfone enxergar as partidas com uma vista ampla, cobrindo todos os setores do gramado e propiciando uma análise mais precisa dos lances. Pode-se aventar, ainda, que o interesse pelas irradiações esportivas ganhou 
novo ânimo com a vitória brasileira na Copa do Mundo de 1958, realizada na Suécia. A necessidade de um especialista, aquele que configura a análise na transmissão, já é, então, uma realidade entre a audiência interessada em ter cada vez mais elementos para a compreensão do ocorrido no palco de ação dos fatos, ou seja, o estádio.

\title{
Fase da crônica esportiva
}

No início da década de 1960, popularizam-se os rádios portáteis transistorizados, a maioria deles contrabandeada do Japão para o Brasil, de onde vêm os da marca Spica, durante algum tempo sinônimo desse novo objeto de desejo e de consumo (FERRARETTO, 2007, p. 90). Na Copa do Mundo de 1962, as transmissões já chegam majoritariamente por meio desse suporte (HAASE, 2002, p. 67), consolidando ainda mais a relação do torcedor com o meio rádio. Com a popularização desse tipo de receptor, alterou-se a maneira pela qual o torcedor relaciona-se com a partida. Passou a ser possível acompanhar o jogo dentro do estádio, ouvindo a transmissão realizada por narradores, repórteres e uma figura que se incorporava, em definitivo, à transmissão: o comentarista de futebol, responsável pela opinião dentro da chamada jornada esportiva.

Desde pelo menos dez anos antes, no entanto, já apareciam profissionais identificados ao microfone como comentaristas, em Porto Alegre: "Aurélio Reis, um dos pioneiros na função, Manoel Godoy de Bezerra, Samuel Madureira Coelho e Enio Melo" (FERRARETTO, 2007, p. 479). Melo atuando, de início, na Rádio Gaúcha e, mais tarde, na Farroupilha, vai se constituir na primeira grande referência da época na função:

\begin{abstract}
Nas edições de 1955 e 1956 do concurso Melhores do Rádio, organizado pela Revista TV, a principal premiação existente na época no estado, Enio Melo aparece como o principal comentarista esportivo gaúcho. Não se limitando a isto, quando se transfere para a [...] Rádio Farroupilha, contribui, também, para a introdução do repórter na transmissão dos jogos de futebol. Esta prática vai tornar obsoleta a chamada narração em diagonal. Para tal, auxilia também o aprimoramento da estrutura física dos estádios, cujo fator principal é a introdução das cabinas de transmissão. (FERRARETTO, 2007, p. 479).
\end{abstract}

Os indícios existentes permitem supor que, nessa época, o comentário radiofônico ainda não possuía uma linguagem própria, aproximando-se do que era realizado em jornais e revistas. Há, assim, um relato romântico, de construção das palavras, fingindo flertar com aspectos da literatura. Ao analisar os gêneros jornalísticos no rádio, Lucht (2010, p. 273) enquadra a crônica no opinativo:

[...] situa-se na fronteira entre a informação da atualidade e a narração literária. Embora mais corriqueira nos meios impressos, no rádio a crônica ganha espaço especialmente durante as transmissões de futebol, quando 
experientes apresentadores/narradores são convidados a falar (muitas vezes de improviso) sobre fatos marcantes ocorridos durante a partida. (LUCHT, 2010, p. 273).

Pode-se supor que o comentário esportivo em Porto Alegre na década de 1950 inclina-se para a crônica, procurando, sem o rigor formal do texto jornalístico mais contemporâneo, explicar as questões táticas e técnicas do jogo ${ }^{6}$, predominando uma visão extremamente pessoal. É importante, portanto, como salienta Dalpiaz (2002, p. 103), reconhecer que, até meados da década seguinte, não há, de modo geral, uma cobertura sistematizada, com pautas e preocupação com os fatos em si. Ruy Carlos Ostermann (2002, apud Dalpiaz, 2002, p. 103), comentarista que iniciou sua carreira na década de 1960, observa que, na época, havia a tradição de um rádio retórico, “com um palavreado bonito, usando expressões cheias, redondas, que davam um colorido especial à frase", sem uma real preocupação com o fato jornalístico em si. Como vai se verificar a seguir, será pela interferência do próprio Ostermann que a situação começa a se alterar, em meados da década de 1960.

\section{Fase do jornalismo esportivo}

Convidado por Jorge Alberto Mendes Ribeiro ${ }^{7}$ para ser comentarista da Rádio Guaíba, Ruy Carlos Ostermann trabalhava na Folha da Tarde Esportiva, um jornal que pertencia, como a emissora, a Breno Caldas. Era professor de filosofia na Universidade Federal do Rio Grande do Sul e jogador de basquete. Começou na Guaíba em 1962 como comentarista esportivo e passou a se destacar a partir de 1963, quando Pedro Carneiro Pereira assumiu a chefia de esportes (MARTINS, 1991, p. 51). A principal contribuição de Ostermann para o período foi dar um tratamento jornalístico ao espaço de opinião na jornada, com a coleta de dados em uma planilha do jogo para organizar a sua análise:

É na Inglaterra, também, que Ruy Carlos Ostermann, ponderando prós e contras, sem deixar de reconhecer o mérito dos adversários, consolida-se como o principal comentarista do Rio Grande do Sul, apresentando explicações para a péssima campanha da Seleção Brasileira [...]. No trabalho que realiza desde então, embasa seus argumentos, analisando a partida pelo número de arremates a gol, de chutes [...], de jogadas bem ou mal finalizadas, escanteios cobrados ou cedidos, de faltas etc. Enfim, uma série de detalhes cuidadosamente planilhados que podem ser resumidos em uma única palavra: informação. (FERRARETTO, 2007, p. 492).

\footnotetext{
${ }^{6}$ A diferença entre as questões táticas e as relativas ao desempenho técnico serão esclarecidas, a seu tempo, quando se tratar, mais adiante, da fase de jornalismo esportivo convergente.

${ }^{7}$ Chefe de esportes da Rádio Guaíba em 1962.
} 
A planilha revolucionou os comentários esportivos a partir da década de 1960. Com base em uma estrutura criada por Ostermann, as informações do jogo eram repassadas para o papel e tomadas como base para retransmitir ao ouvinte os números relevantes para a interpretação dos fatos do jogo:

Testei um pouquinho e depois adotei mecanicamente. Com base nisto que está à minha frente, e que eu vou preenchendo, tenho todas as informações do jogo em duas folhas. Então meu comentário, por força disso, ficou completamente diferente dos outros, eu não tinha que fazer uma frase de efeito. Eu partia do seguinte: o Grêmio foi superior ao Internacional por uma razão bem simples. O Grêmio chutou 22 vezes e o Internacional, quatro. Vocês querem uma comprovação mais clara de uma diferença entre um e outro, que esta? [...] Tinha que dizer: o Grêmio domina, é insistente, tem mais volume. Tudo isso é verdade, só que o que faltava era dizer como que era isso. Então o comentário ficou revestido de veracidade. [...] Acrescento os números para comprovação material de tudo. (OSTERMANN, 2002 apud DALPIAZ, 2002, p. 107).

Com a chegada de Ostermann, observava-se, pela primeira vez, a partir da captura de dados para embasar as opiniões, um profissional relacionar a informação com a opinião no comentário esportivo no rádio de Porto Alegre. O sistema foi imediatamente incorporado à prática dos analistas da época. Lauro Quadros (Informação verbal, 27 jun. 2016) ${ }^{8}$, que passou a atuar na função no final da década de 1960, destaca o papel do colega de emissora: "foi uma revolução no comentário, que se divide entre antes e depois de Ruy Carlos Ostermann".

Diante desse cenário, o comentarista, que na fase da crônica esportiva trabalhava predominantemente com o gênero opinativo, passou a usar a informação e, por vezes, a se inclinar, sem abandonar a opinião em si, para o interpretativo. $\mathrm{O}$ processo coincide com as transmissões de jogos de futebol pela televisão. A primeira delas ocorre, bem antes, em 15 de outubro de 1950, entre Palmeiras e Santos no Pacaembu (RIBEIRO, 2007, p. 135), mas a prática radiofônica vai atravessar as décadas seguintes restrita às partidas decisivas dos principais eventos, ganhando força a partir da Copa do Mundo do México, em 1970, a primeira transmitida ao vivo para o Brasil, e da Taça da Independência, o evento cuja difusão pela TV em 1972 foi incentivada pelo Governo Militar durante os festejos do Sesquicentenário da Independência brasileira. Tal prática, no entanto, começa a se alterar com a ida de Luciano do Valle, então o principal narrador da Rede Globo de Televisão, para a Rede Bandeirantes, em 1983 (NOVO..., 9 nov. 1983, p. 140). As estações do grupo da família Saad passam a abrir espaços

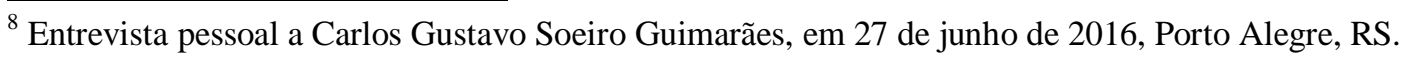


crescentes para o esporte, em especial para o futebol. Nesse processo, gradativamente, a transmissão televisiva determina sensíveis alterações. O que antes passava apenas pelo imaginário do torcedor - muitas vezes, como uma mera corroboração da opinião do comentarista por uma simples ausência de elementos que pudessem dar ao público a sua visão do acontecimento - dá lugar à imagem em si na tela do aparelho de TV.

Cabe observar que, mesmo adotando a prática de planilhar dados, há diferenças de estilo entre os principais comentaristas desse período no rádio de Porto Alegre. Se Ruy Carlos Ostermann tem um tom quase professoral - ora contextualizando e pendendo para o interpretativo, ora fazendo uma crônica e tendendo ao diversional -, Lauro Quadros acrescenta "descontração a uma atividade em que o ouvinte ainda é chamado, com cerimônia, de senhor" e "consagra expressões como 'esse conhece o rengo sentado e o cego dormindo' ou 'ele sabe a cabeça que tem piolho', para definir profissionais ou elogiar lances de brilhantismo; 'ali é o caminho da roça', indicando uma área do campo de marcação deficiente do adversário, por onde um time pode chegar ao gol; ou 'é isto aí mais meio quilo de farofa', forma de encerrar um raciocínio" (FERRARETTO, 2007, p. 493). Quadros, no entanto, não se resumia a essas práticas mais conotativas:

A transição de repórter para comentarista foi natural na medida em que eu passei minha linguagem de repórter, que era uma linguagem descontraída, uma linguagem de vanguarda, avançada para a época. Eu comunicava com o povo e transferi isso para o comentário. O pessoal se fixa muito nos meus bordões, mas eu não descuidava das questões técnicas do jogo. (QUADROS, informação verbal, 27 jun. 2016).

Ruy Carlos Ostermann e Lauro Quadros praticamente dominavam o comentário esportivo no rádio comercial de Porto Alegre nas décadas de 1970 e 1980. Na época, também se destacam comentaristas com perfil de torcedor - caso de Paulo Sant'Ana, identificado com o Grêmio Foot-ball Porto-alegrense, e Kenny Braga, com o Sport Club Internacional - e/ou diretamente relacionados com o esporte - caso dos ex-dirigentes Ibsen Pinheiro, Cid Pinheiro Cabral e Cláudio Cabral ou do ex-técnico Osvaldo Rolla, o Foguinho. A maioria desses profissionais passaria pelo microfone da Rádio Gaúcha, que, a partir de 1986, passa a liderar o segmento de jornalismo, ocupando, guardadas as diferenças de cada época, a posição anteriormente da Guaíba.

Quando chega a década de 1990, como observa Dalpiaz (2002, p. 134), o espetáculo esportivo já se transformara em ativo importante das indústrias culturais ${ }^{9}$,

\footnotetext{
${ }^{9}$ Adota-se aqui a ideia de Zallo (1988, p. 26): "um conjunto de ramificações, segmentos e atividades industriais auxiliares produtoras e distribuidoras de mercadorias com conteúdos simbólicos, concebidas
} 
além de se consolidar como veículo de marketing para patrocinadores. Outras emissoras, além de Guaíba e Gaúcha, montam equipes esportivas, nas quais predominam comentaristas, cuja prática oscila entre os gêneros opinativo e interpretativo. Gradativamente, vão começar a coexistir com um novo estilo de analista, motivado pela presença da internet, na segunda metade daquela década.

\section{Fase do jornalismo esportivo convergente}

A popularização da internet redesenhou, de certa forma, as práticas profissionais dos jornalistas. Ferraretto e Kischinhevsky (2010, p. 6) constatam que há uma mudança gerada pelas possibilidades de integração do rádio com as plataformas digitais, em um cenário de crescente convergência, que reconfigura a lógica do meio. Parte-se do princípio da cultura convergente, "que ocorre dentro dos cérebros dos consumidores individuais e suas relações sociais com outros" (JENKINS, 2006, p. 28). Entre os âmbitos da convergência aplicados ao rádio, Ferraretto e Kischinhevsky (2010, p. 4) relacionam as transformações tecnológicas, empresariais, profissionais e nos conteúdos com novas experiências proporcionadas pela audiência, com "ouvintes que emulam serviços de reportagem ao se comunicarem com emissoras para informar, por exemplo, sobre o trânsito" (FERRARETTO; KISCHINHEVSKY, 2010, p. 3).

Nesse contexto, a possibilidade que o ouvinte tem de interagir altera, de modo significativo, as suas conexões com os produtores do conteúdo radiofônico. Os comentaristas esportivos também precisaram compor novos significados para as suas práticas, justamente pelas demandas do público, agora constituído, como define Castells (2015), como audiência criativa, "uma audiência ativa que molda seu significado ao contrastar suas experiências com os fluxos unilaterais de informação que ela recebe", representando "o surgimento da produção interativa de significado" e se constituindo na "fonte de cultura da remixagem que caracteriza o mundo de autocomunicação de massa" (CASTELLS, 2015, p. 186).

Castells (2015, p. 183) define como autocomunicação de massa a ativação de sujeitos comunicativos que determinam tanto o conteúdo quanto o destino da mensagem e são simultaneamente seus emissores e receptores nos fluxos multidirecionais. Se, nas fases anteriores, as análises dos comentaristas de rádio serviam como uma espécie de decreto a respeito de uma partida de futebol, sob o jornalismo esportivo convergente, a

por um trabalho criativo, organizadas por um capital que se valoriza e destinadas, finalmente, aos mercados de consumo, com uma função de reprodução ideológica e social”". 
lógica multidirecional passa a dominar. Via redes sociais, o público tem condições de expressar sua própria análise do jogo.

Nesse novo contexto, o dado técnico, mesmo podendo ser de difícil assimilação pela audiência em geral, ganha relevo. A consequência direta na prática dos comentaristas é buscar a especialização e o aprimoramento técnico para explicar os detalhes da partida. Trata-se de processo que aproxima o seu resultado - o conteúdo do que, décadas atrás, Alberto Dines (1974 apud RABAÇA; BARBOSA, 1987, p. 346) reivindicava como gênero interpretativo: a possibilidade de ampliação da informação, ao serem incluídos elementos como a dimensão comparada, a remissão ao passado, a interligação com outros fatos, a incorporação do fato a uma tendência e a sua projeção para o futuro. Nesse sentido, cabe destacar que o conjunto de informações qualificadas faz o jornalismo interpretativo.

Um dos principais comentaristas do rádio de Porto Alegre na atualidade, Nando Gross começou a trabalhar na fase do jornalismo esportivo, tendo passado por emissoras como Bandeirantes, Gaúcha e, desde 2014, Guaíba, onde também faz a gestão de conteúdo. Segundo esse profissional, foi necessária uma adaptação ao novo estilo, por força da audiência mais participativa:

Foi uma evolução natural das coisas. É uma exigência das pessoas. Elas discutem mais o jogo que antes, estão mais informadas. O público quer saber mais sobre os detalhes do jogo. É como um vendedor, que antigamente enrolava. Hoje, as pessoas pesquisam mais na internet sobre os produtos que elas querem comprar. É preciso que esse vendedor acrescente algo que o público não saiba. [...] Antigamente, não havia este aprofundamento e, justamente em função dessa demanda, o comentarista passou a estudar mais para explicar questões do jogo que são mais técnicas e especializadas. (GROSS, informação verbal, 20 jun. 2016) ${ }^{10}$.

A principal mudança diz respeito à importância das questões táticas para a compreensão do jogo, algo que, de acordo com Lauro Quadros (Informação verbal, 27 jun. 2016), era tratado com superficialidade, com mais ênfase nos aspectos individuais e técnicos, ao contrário da atualidade, quando convivem abordagens mais coletivas e táticas sobre o jogo. Neste ponto, são necessários alguns esclarecimentos. Conceito oriundo da abordagem científica do esporte, a análise tática consiste, entre outros procedimentos, em identificar a distribuição da equipe em campo e avaliar os comportamentos individuais e coletivos do time, atribuir resultados às chamadas fases de jogo e verificar qual o sistema tático empregado. A sua aplicação ao jornalismo esportivo, feita aqui, se baseia em Cecconi (2013, p. 7), que define a técnica como

\footnotetext{
${ }^{10}$ Entrevista pessoal a Carlos Gustavo Soeiro Guimarães, em 20 de junho de 2016, Porto Alegre, RS.
} 
forma de "compreensão dos movimentos do jogo". Já a análise de desempenho é utilizada pelos treinadores para "auxiliar o planejamento dos dados" (CECCONI, 2013, p.12) e, em sua aplicação aos comentários esportivos, para "organizar os conteúdos individuais e coletivos detalhados para auxiliar na compreensão do jogo" (FOGAÇA, informação verbal, 20 jun. 2016) ${ }^{11}$.

Alguns comentaristas, portanto, em um processo que pode crescer, passam a alicerçar suas posições nas análises tática e de desempenho. A Rádio Gaúcha, por exemplo, contratou Gustavo Fogaça para ir ao encontro desse processo. Para o comentarista, a análise de desempenho fornece "ao público dados analíticos que entregam ao público situações de jogo específicas baseadas em dados, no rádio e nas plataformas digitais" (FOGAÇA, informação verbal, 20 jun. 2016). Na atualidade, profissionais de outras emissoras também utilizam aplicativos e plataformas on-line para descrever os números do jogo e desenhar o panorama tático da partida. Termos como amplitude ${ }^{12}$, profundidade ${ }^{13}$ e avaliação do mapa de calor $^{14}$ dos atletas pertencem a esse novo campo a ser explorado, em uma aproximação com o da Educação Física. Gustavo Fogaça avalia que esse cenário se fortaleceu bastante após o episódio da derrota da Seleção do Brasil para a da Alemanha, em 8 de julho de 2014, na semifinal da Copa do Mundo, pelo placar de 7 a 1:

O rádio esportivo brasileiro está mudando, não só em Porto Alegre. O fato positivo dos 7 a 1 foi que aquele resultado levou o público a querer se aprofundar sobre o jogo. O mundo mudou nos últimos 15 anos. As estruturas organizacionais passaram a ser horizontais. $O$ jeito de trabalhar $o$ conhecimento mudou. O compartilhamento do conhecimento mudou graças ao que as redes sociais oferecem ao mundo inteiro. [...] Esse acesso tão rápido a todo tipo de informação faz com que o espectador saiba tanto ou mais que você. A audiência exige ferramentas que lhes dão a possibilidade de expansão do próprio conhecimento que eles já têm. (FOGAÇA, informação verbal, 20 jun. 2016).

Desse modo, quando opta pelas análises tática e de desempenho, o comentarista esportivo coloca um pé no jornalismo interpretativo e, ao usar as informações para embasar seus posicionamentos a respeito de um jogador, técnico ou mesmo de uma equipe, põe o outro pé no gênero opinativo. Também ocorre uma resposta da parcela da

\footnotetext{
${ }^{11}$ Entrevista pessoal a Carlos Gustavo Soeiro Guimarães, em 20 de junho de 2016, Porto Alegre, RS.

12 Tentativa de abrir as linhas adversárias, distribuindo jogadores de uma ponta a outra do campo ofensivo.

${ }^{13}$ Oferta de opções de passe à frente, na direção da linha de fundo, com maior possibilidade, portanto, de se chegar ao gol.

${ }^{14} \mathrm{O}$ mapa de calor monitora as regiões do campo nas quais os jogadores mais tocaram na bola. E, assim, ele apresenta um diagrama colorido de cada atleta.
} 
audiência mais informada, que reflete sobre a mensagem do profissional, tudo a reafirmar a cultura da convergência.

\section{Considerações finais}

No descrito até aqui a respeito da periodização proposta para a trajetória do comentário esportivo no rádio de Porto Alegre, foram demarcados, como pede a metodologia histórica, pontos de corte. Entretanto, outros fatores - como característica, causa ou consequência - também são primordiais para a determinação desses rompimentos. O Quadro 1 procura identificar outros pontos, indicando as principais distinções entre as fases ao delimitar princípios normativos, comportamentos da audiência e gêneros jornalísticos predominantes.

Quadro 1 - Detalhamento da proposta de periodização do comentário esportivo em Porto Alegre.

\begin{tabular}{|c|c|c|c|}
\hline Fase & Características & Audiência & Gênero \\
\hline 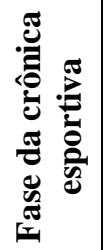 & $\begin{array}{l}\text { Opinião baseada em mera } \\
\text { observação, sem o tratamento } \\
\text { do conteúdo. } \\
\begin{array}{l}\text { Estrutura do comentário } \\
\text { semelhante ao de uma } \\
\text { crônica. }\end{array} \text { a }\end{array}$ & $\begin{array}{l}\text { Trabalha com a versão do } \\
\text { comentarista. } \\
\text { Graças ao radinho de pilha, } \\
\text { pode escutar a irradiação e } \\
\text { assistir ao jogo no campo, } \\
\text { simultaneamente. }\end{array}$ & Opinativo. \\
\hline 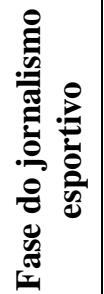 & $\begin{array}{l}\text { Dados planilhados. } \\
\text { Tratamento jornalístico. } \\
\text { Questões técnicas são } \\
\text { prioritárias. }\end{array}$ & $\begin{array}{l}\text { Pode, além da escuta no } \\
\text { estádio, receber o áudio da } \\
\text { emissora de rádio enquanto } \\
\text { assiste ao jogo pela televisão. } \\
\text { Pode ter, graças à imagem da } \\
\text { TV, seu próprio juízo de valor a } \\
\text { respeito da partida em si. }\end{array}$ & $\begin{array}{l}\text { Opinativo, com } \\
\text { incursões } \\
\text { pelo interpretativo. }\end{array}$ \\
\hline 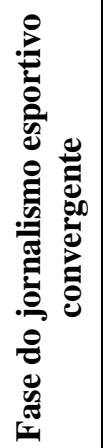 & $\begin{array}{l}\text { Influência, via redes sociais, } \\
\text { de uma parcela de audiência } \\
\text { mais informada. } \\
\text { Questões técnicas não são as } \\
\text { únicas a pesarem nos } \\
\text { comentários. } \\
\text { Questões táticas e de } \\
\text { desempenho ganham espaço. }\end{array}$ & $\begin{array}{l}\text { Pelas redes sociais, emite } \\
\text { opinião embasada ou não. } \\
\text { Múltiplas possibilidades: ouvir } \\
\text { o jogo e ver ao vivo no campo, } \\
\text { na televisão ou em suportes } \\
\text { móveis; acompanhar dados; } \\
\text { interagir e influenciar. } \\
\text { É, em tese, mais colaborativa, } \\
\text { exigente e informada. }\end{array}$ & $\begin{array}{l}\text { Opinativo, com } \\
\text { interpretativo } \\
\text { tendendo a ganhar } \\
\text { mais força. }\end{array}$ \\
\hline
\end{tabular}

Fonte: Dados da pesquisa. 
Considera-se que, para chegar à ruptura que corta cada período, há uma dinâmica iniciada na fase anterior. Esse tensionamento entre o modelo hegemônico vigente e uma nova prática gera um processo, que, ao se tornar dominante, origina outro padrão predominante. Com isso, julga-se incorreto afirmar que as características de uma fase desaparecem totalmente na seguinte. Supõe-se uma coexistência de modelos até a gradativa superação de uns por outros. No entanto, vale uma ressalva. Embora aqui não se tenha adentrado o terreno das alterações constatadas ao longo do tempo no próprio sistema capitalista com reflexos no mercado de rádio, cabe observar que se tem consciência de que as transformações verificadas no comentário esportivo ocorrem sob a necessidade de adaptação do meio, como negócio, ao surgimento de concorrentes como a televisão ou a internet e seus correlatos. Por ser recente e estar em curso ainda, a fase do jornalismo esportivo convergente requer certo cuidado na sua análise, próprio do estudo de processos em andamento. De outra parte, isso apenas atesta a necessidade de estudá-la. Novas características foram processadas até que esse padrão começasse a se desenvolver. Para compreendê-la, talvez seja necessário retomar, como indícios, aspectos dos períodos históricos anteriores. São passos que ficam como desafios a partir desta abordagem inicial.

\section{Referências}

BRITTOS, Valério Cruz. O rádio brasileiro na fase da multiplicidade da oferta. Verso \& Reverso, São Leopoldo, ano 16, n. 35, p. 31-54, jul.-dez. 2002.

CASTELLS, Manuel. O poder da comunicação. São Paulo: Paz e Terra, 2015.

CECCONI, Eduardo. Análise tática de futebol no jornalismo esportivo. [s.1.]: [s.e], 2013. Disponível em: <https://pt.scribd.com/doc/157490286/Analise-tatica-de-futebol-nojornalismo-esportivo>. Acesso em: 18 maio 2016.

DALPIAZ, Jamile Gamba. O futebol no rádio de Porto Alegre: um resgate histórico (dos anos 30 à atualidade). Porto Alegre. 2002. 187 f. Dissertação (Mestrado em Comunicação e Informação) - Faculdade de Biblioteconomia e Comunicação, Universidade Federal do Rio Grande do Sul, 2002.

FERRARETTO, Luiz Artur. Rádio no Rio Grande do Sul (anos 20, 30 e 40): dos pioneiros às emissoras comerciais. Canoas: Editora da Ulbra, 2002.

Rádio e capitalismo no Rio Grande do Sul: as emissoras comerciais e suas estratégias de programação na segunda metade do século 20. Canoas: Editora da Ulbra, 2007.

Uma proposta de periodização para a história do rádio no Brasil. Eptic - 
Revista de Economia Política das Tecnologias da Informação e Comunicação, Observatório de Economia e Comunicação da Universidade Federal do Sergipe, Aracaju, v. XIV, n. 2, maio-ago. 2012.

Rádio: teoria e prática. São Paulo: Summus, 2014.

FERRARETTO, Luiz Artur; KISCHINHEVSKY, Marcelo. Rádio e convergência: uma abordagem pela economia política da comunicação. In: ENCONTRO ANUAL DA COMPÓS, 19., 2010, Rio de Janeiro. Anais... Rio de Janeiro: Associação Nacional dos Programas de Pós-Graduação em Comunicação, 2010.

FOGAÇA, Gustavo. Comentarista da Rádio Gaúcha. Entrevista pessoal a Carlos Gustavo Soeiro Guimarães, em 20 de junho de 2016, Porto Alegre, RS.

GROSS, Nando. Comentarista esportivo da Rádio Guaíba. Entrevista pessoal a Carlos Gustavo Soeiro Guimarães, em 20 de junho de 2016, Porto Alegre, RS.

HAASE FILHO, Pedro (Coord.). Brasil nas copas: em destaque, a participação dos gaúchos. Porto Alegre: ZH Publicações, 2002.

HELLER, Agnes. Teoría de la historia. 5. ed. México: Fontamara, 1997.

JENKINS, Henry. Cultura da convergência. São Paulo: Aleph, 2006.

LUCHT, Janini Marques Passini. Gêneros no radiojornalismo. In: MELO, José Marques de; ASSIS, Francisco de (Org.). Gêneros jornalísticos no Brasil. São Bernardo do Campo: Universidade Metodista de São Paulo, 2010, p. 269-290.

MARTINS, Carlos Henrique da Motta. O desenvolvimento do rádio esportivo em Porto Alegre. São Leopoldo, 1991. 72 f. Monografia (Comunicação Social Habilitação em Jornalismo) - Departamento de Comunicação e Jornalismo da Universidade do Vale do Rio dos Sinos, 1991.

MELO, José Marques de; ASSIS, Francisco de (Org.). Gêneros jornalísticos no Brasil. São Bernardo do Campo: Universidade Metodista de São Paulo, 2010.

MOSCO, Vincent. The political economy of communications: rethinking and renewal. Londres: Sage, 1996.

NOVO endereço. Luciano do Valle agora na Bandeirantes. Veja, São Paulo, ano 16, n. 792, p. 140, 9 nov. 1983.

QUADROS, Lauro. Ex-comentarista das rádios Gaúcha e Guaíba. Entrevista pessoal a Carlos Gustavo Soeiro Guimarães, em 27 de junho de 2016, Porto Alegre, RS.

RABAÇA, Carlos Alberto; BARBOSA, Gustavo Guimarães. Dicionário de Comunicação. São Paulo: Ática, 1987.

RIBEIRO, André. Os donos do espetáculo: histórias da imprensa esportiva do Brasil. São Paulo: Terceiro Nome, 2007. 
SCHUDSON, Michael. Enfoques históricos a los estudios de la comunicación. In: JENSEN, Klaus Bruhn; JANKOWSKI, Nicholas W. (Org.). Metodologías cualitativas de investigación en comunicación de masas. Barcelona: Bosch, 1993. p. 211-228.

ZALLO, Ramón. Economía de la comunicación y la cultura. Madri: Akal, 1988.

Submetido em: 24.10 .2016

Aprovado em: 04.06.2017 